RELATO DE CASO

ISSN 1677-5090

(C) 2019 Revista de Ciências Médicas e Biológicas

http://dx.doi.org/10.9771/cmbio.v18i3.34133

\title{
Tumor marrom do hiperparatireoidismo: relato de caso
}

\author{
Brown hyperparatireoidism tumor: case report
}

\begin{abstract}
Ana Paula Menezes Vaz Queiroz ${ }^{1}$, João Frank Carvalho de Oliveira², Patrícia Miranda Leite Ribeiro ${ }^{3 *}$
${ }^{1}$ Mestranda do Programa de Pós-Graduação em Processos Interativos dos Órgãos e Sistemas do Instituto de Ciências da Saúde da Universidade Federal da Bahia (UFBA).; ' Doutorado em Odontologia pela Universidade Federal da Paraíba (UFPB). Professor adjunto da Faculdade de Odontologia da Universidade Federal da Bahia (FOUFBA).; ${ }^{3}$ Doutorado em Odontologia pela Universidade Federal da Paraíba (UFPB). Professora adjunta da Faculdade de Odontologia da Universidade Federal da Bahia (FOUFBA). Docente do Programa de Pós-Graduação em Processos Interativos dos Órgãos e Sistemas do Instituto de Ciências da Saúde da Universidade Federal da Bahia.
\end{abstract}

\begin{abstract}
Resumo
Introdução: a prevalência de doenças endócrino-metabólicas, como, por exemplo, o hiperparatireoidismo, tem crescido com a melhoria da expectativa de vida da população e pode levar a alterações no sistema estomatognático. Objetivo: relatar um caso clínico de um paciente com diagnóstico de tumor marrom associado ao hiperparatireoidismo. Metodologia: a metodologia adotada neste artigo foi o relato de caso, através da revisão de prontuário de um paciente atendido no ambulatório da disciplina de Estomatologia II na Faculdade de Odontologia da Universidade Federal da Bahia. Resultados: Clinicamente, observou-se um aumento de volume da hemiface esquerda e, radiograficamente, pôde-se observar imagem radiopaca envolvendo processo alveolar e seio maxilar esquerdo. Além disso, os exames laboratoriais mostraram elevados níveis do hormônio paratireoidiano. Conclusão: as características clínicas, radiológicas e histológicas das lesões de tumor marrom devem ser analisadas junto à condição sistêmica do indivíduo, a fim de propiciar correto diagnóstico e intervenção precisa.
\end{abstract}

Palavras-chave: Saúde Bucal. Hiperparatireoidismo. Células gigantes.

\begin{abstract}
Introduction: the prevalence of endocrine-metabolic diseases, such as hyperparathyroidism, has increased with the improvement in life expectancy of the population and may lead to changes in the stomatognathic system.Objective: to report a clinical case of a patient diagnosed with brown tumor associated with hyperparathyroidism. Methodology: methodology adopted in this article was the case report, through the review of the medical records of a patient treated at the outpatient clinic of Stomatology II at the School of Dentistry of the Federal University of Bahia. Results: clinically, an enlarged left hemiface was observed, and radiographically, a radiopaque image involving the alveolar process and left maxillary sinus could be observed. In addition, laboratory tests showed high levels of parathyroid hormone. Conclusion: clinical, radiological and histological characteristics of brown tumor lesions should be analyzed with the individual's systemic condition, in order to provide correct diagnosis and precise intervention.
\end{abstract}

Keywords: Oral Health. Hyperparathyroidism. Giant Cells

\section{INTRODUÇÃO}

As glândulas paratireoides são responsáveis pela produção do hormônio paratireoidiano (PTH), e o aumento de produção desse hormônio pode causar o hiperparatireoidismo, gerando uma série de alterações sistêmicas, inclusive no tecido ósseo ${ }^{1}$. O hiperparatireoidismo pode ser primário, associado a adenomas ou hiperplasias da glândula, ou secundário, em decorrência da diminuição crônica nos níveis séricos de cálcio em pacientes nefropatas, por insuficiência renal crônica ${ }^{1}$.

O hiperparatireoidismo (primário ou secundário) pode resultar em uma lesão óssea denominada de "tumor marrom", que pode ser diferenciada de outras lesões pela

Correspondente/Corresponding: *Patrícia Miranda Leite Ribeiro Faculdade de Odontologia da Universidade Federal da Bahia. - Av. Araújo Pinho, 62 - Canela, CEP: 40110-060, Salvador - BA. Tel: (71) 99141-7949. — E-mail: patrícia. leiteribeiro@gmail.com. combinação dos achados clínicos e radiográficos, além de exames laboratoriais ${ }^{2,3}$. A conduta terapêutica diferenciada e individualizada é importante, pois um diagnóstico malsucedido pode gerar terapêuticas mais invasivas de forma desnecessária ${ }^{1}$.

O objetivo deste trabalho foi descrever uma lesão encontrada em uma paciente portadora de hiperparatireoidismo e correlacionar o hiperparatireoidismo com o seu quadro clínico, comparando com outras possíveis lesões. É importante a compreensão desse conhecimento para guiar as condutas das equipes odontológicas de atenção aos indivíduos.

\section{METODOLOGIA}

A paciente autorizou a utilização dos dados de seu caso por escrito, concordando com o Termo de Consentimento Livre e Esclarecido, seguindo-se, assim, os prin- 
cípios éticos de estudo. Este relato de caso foi registrado no CONEP com o número CAAE: 13980619.2.0000.5024.

RELATO DE CASO

Paciente de 39 anos, do sexo feminino, compareceu ao ambulatório de Estomatologia II da FOUFBA, com queixa de perdas dentárias e aumento de volume na face.

Em exame clínico, notou-se uma grande assimetria facial, com aumento de volume na hemiface esquerda. No exame intrabucal, observou-se a presença de mobilidade dentária generalizada, além de aumento de volume em região de processo alveolar esquerdo da maxila, envolvendo regiões anterior e posterior vestibular e do palato, sem presença de sinais infecciosos.

Através de radiografia panorâmica, foi identificada imagem radiopaca envolvendo processo alveolar e seio maxilar esquerdo, e ausência de lâmina dura.

Figura 1 - Exame de imagem: radiografia panorâmica.

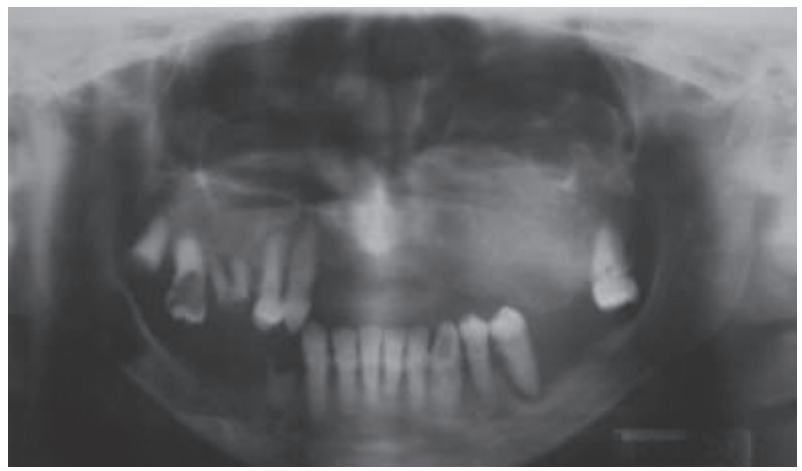

Fonte: Autoria própria

No exame de tomografia computadorizada multislice, notou-se a presença de imagem hiperdensa expansiva, de aspecto trabecular, em região anterior e posterior da maxila esquerda, envolvendo processos alveolares, seio maxilar até proximidade de assoalho de órbita.

Figura 2 - Tomografia computadorizada mostrando lesão em maxila.

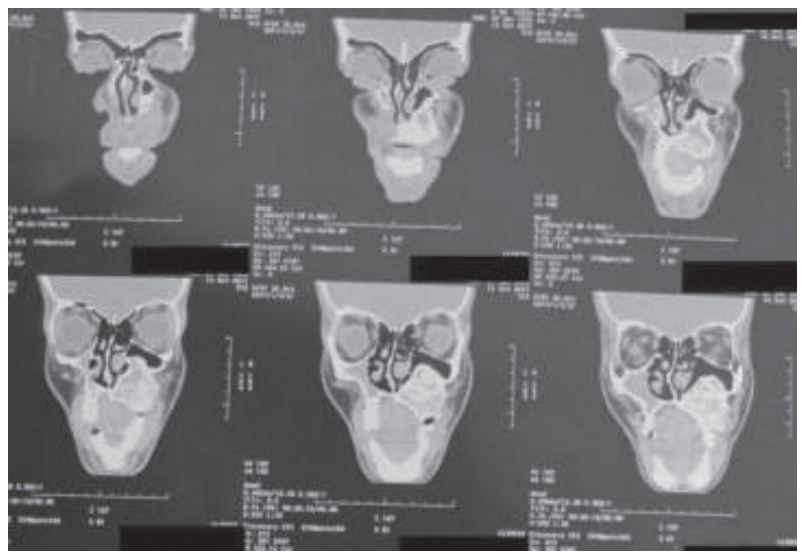

Fonte: Autoria própria
Figura 3 - Tomografia computadorizada com lesão expansiva bem delimitada do lado esquerdo, ocupando parcialmente o seio.

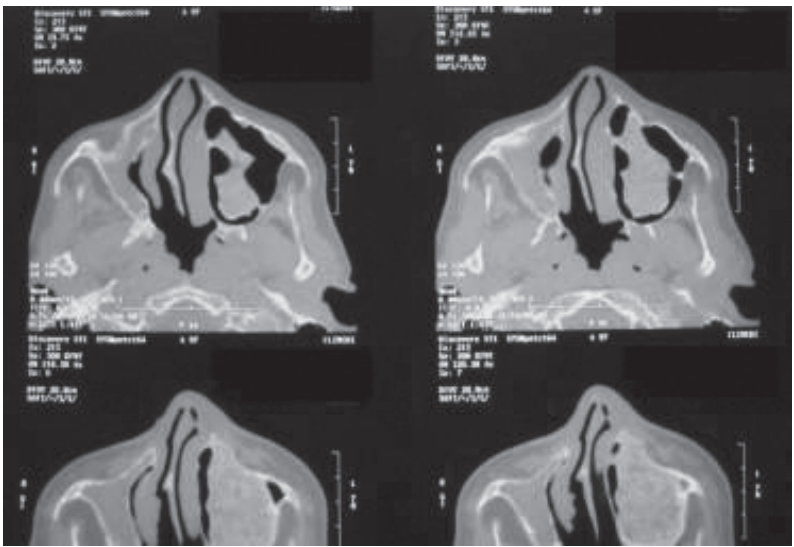

Fonte: Autoria própria

Foi realizada biópsia incisional, sob anestesia local, em cavidade bucal, com o resultado indicando tumor de células gigantes. Foi solicitado exame laboratorial, no qual se notaram elevados níveis de PTH. Devido aos achados clínicos, laboratoriais, tomográficos e histopatológicos, chegou-se ao diagnóstico de tumor marrom.

A paciente foi encaminhada ao acompanhamento de endocrinologista para normalização dos níveis de PTH, e houve regressão da lesão.

\section{DISCUSSÃO}

A condição sistêmica do indivíduo pode influenciar o desenvolvimento do sistema ósseo. Segundo Santana et $a .^{4}{ }^{4}$, um desequilíbrio hormonal no quadro clínico do paciente pode resultar em uma lesão óssea focal, denominada de "tumor marrom", que comumente afeta ossos longos como os do fêmur e quadril, bem como das costelas, clavículas e vértebras, sendo menos frequente na maxila e na mandíbula.

O tumor marrom apresenta, em suas características clínicas, o aumento de volume tecidual de crescimento lento, e algumas lesões simulam tumores malignos, porque se comportam de forma mais destrutiva ${ }^{4}$. Histologicamente, o tumor marrom apresenta dois componentes celulares principais: células estromais mononucleadas e células gigantes multinucleadas, com caráter invasivo em alguns casos, mas sem potencial neoplásico ${ }^{4,5}$. Radiograficamente, segundo a literatura, podem-se observar lesões radiolúcidas, semelhantes a lesões císticas, bem delimitadas uni ou multiloculadas ${ }^{1}$, embora, em nosso caso, a imagem tenha mostrado áreas radiopacas.

As células gigantes multinucleadas são encontradas em outras lesões benignas, como, por exemplo, no granuloma central e periférico de células gigantes e no cisto ósseo aneurismático. No tumor marrom do hiperparatireoidismo, elas ficam em meio a seu estroma 2,3 . Concordando quanto às semelhanças dessas lesões, Martins et $a l .{ }^{1}$ relataram que a lesão de tumor marrom 
é histologicamente igual à lesão central de células gigantes dos maxilares. Essa última é benigna, embora seja localmente agressiva. Portanto um diagnóstico precoce e malsucedido pode causar condutas terapêuticas radicais desnecessárias e graves sequelas, pois os tratamentos são diferentes.

O diagnostico diferencial é fundamental para predizer a conduta terapêutica ${ }^{2,3}$. 0 exame de laboratório permite investigar as taxas hormonais, sendo que, no hiperparatireoidismo, há aumento na produção do PTH, modificando o metabolismo do cálcio e do fósforo e gerando uma série de alterações sistêmicas, inclusive no tecido ósseo ${ }^{1}$. Em concordância, Pinto et al. ${ }^{5}$ afirma, em seu estudo, que modificações no PTH alteram a relação entre o cálcio intra e extracelular, aumentando a reabsorção óssea, diminuindo sua densidade e levando ao depósito de cálcio nos tecidos moles. Sendo assim, a investigação, com os exames laboratoriais, auxilia no diagnóstico, pois, em casos de tumor marrom, a dosagem de cálcio, fósforo, fosfatase alcalina e PTH sofre alterações, enquanto, nas outras lesões, não há modificação ${ }^{4}$.

Após o diagnóstico de tumor marrom, o tratamento da lesão deve ser feito com o médico endocrinologista, com o tratamento do hiperparatireoidismo, a fim de promover o controle dos níveis de PTH e posterior verificação de regressão da lesão. $O$ estudo de Reis et al. ${ }^{6}$ mostraram um caso semelhante, no qual o tratamento da lesão foi conservador, e os autores relatam que foi obtida uma discreta regressão da lesão após a paratireoidectomia total. Todavia Santana et al. ${ }^{4}$ relatam, em seu estudo, que foi realizada a terapia medicamentosa, mas a lesão não regrediu. Sendo assim, optaram pela remoção da glândula paratireoide do paciente, embora, após mais de um ano de sua remoção, o quadro clínico intrabucal ainda não apresentasse alterações significantes.

\section{CONCLUSÃO}

O hiperparatireoidismo, quando na presença de lesão de células gigantes, deve ser investigado mais a fundo, pois alterações nos níveis hormonais sugerem o diagnóstico de tumor marrom. Além disso, a conduta terapêutica conservadora da lesão é mais recomendada, tendo em vista seu caráter menos traumático e um prognóstico favorável, principalmente quando associada ao acompanhamento com o médico endocrinologista. É importante ressaltar a importância da avaliação individual de cada caso para determinação da conduta a ser adotada.

\section{REFERÊNCIAS}

1. MARTINS, R. et al. Tumor marrom bilateral do hiperparatiroidismo primário em mandíbula: relato de caso. Rev. Clín. Pesq. Odontol., Curitiba, v. 6, n.2, p.185-190, maio/ago. 2010.

2. NOGUEIRA, R. L. M. et al. Lesão de células gigantes: um estudo do diagnóstico diferencial em 04 casos clínicos. Rev. Cir. Traumatol. Buco-Maxilo-Fac., Camarigibe, v. 4, n. 2, p. 81-89, abr. /jun.2004.

3. NOLETO, J. W. et al. Aspectos radiológicos e epidemiológicos do granuloma central de células gigantes. Radiol. Bras., Rio de Janeiro, v. 40, n. 3, p. 167-171, 2007.

4. SANTANA, P. H. G. et al. Tumor marrom em maxila associado ao hiperparatireoidismo secundário: relato de caso clínico. J. Health Sci. Inst., São Paulo, v. 35, n.1, p. 55-58, 2017.

5. PINTO, M. C. et al. Brown tumor in a patient with hyperparathyroidism secondary to chronic renal failure. Braz. J. Otorhinolaryngol., São Paulo, v. 76, n. 3, p. 404, 2010.

6. REIS, D. A. et al. Secondary hyperparathyroidismwith facial deformity (leontiasis ossea). Rev. Bras. Cir. Craniomaxilofac., São Paulo, v. 14. n.2. p. 108-110, 2011

Submetido em: $11 / 12 / 2019$

Aceito em: 12/12/2019 